Supplementary Material for

\title{
Cloud impacts on photochemistry: a new climatology of photolysis rates from the Atmospheric Tomography mission
}

\author{
Samuel R. Hall ${ }^{1}$, Kirk Ullmann ${ }^{1}$, Michael J. Prather ${ }^{2}$, Clare M. Flynn ${ }^{2}$, Lee T. Murray ${ }^{3}$, Arlene M. Fiore ${ }^{4,5}$, \\ Gustavo Correa $^{4}$, Sarah A. Strode ${ }^{6,7}$, Stephen D. Steenrod ${ }^{6,7}$, Jean-Francois Lamarque ${ }^{1}$, Jonathon Guth ${ }^{8}$, \\ Béatrice Josse $^{8}$, Johannes Flemming ${ }^{9}$, Vincent Huijnen ${ }^{10}$, N. Luke Abraham ${ }^{11,12}$, Alex T. Archibald ${ }^{11,12}$ \\ ${ }^{1}$ Atmospheric Chemistry, Observations and Modeling Laboratory, National Center for Atmospheric Research, \\ Boulder, CO 80301, USA \\ ${ }^{2}$ Department of Earth System Science, University of California, Irvine, CA, USA \\ ${ }^{3}$ Department of Earth and Environmental Sciences, University of Rochester, Rochester, NY, USA \\ ${ }^{4}$ Department of Earth and Environmental Sciences, Columbia University, NY, NY, USA \\ ${ }^{5}$ Lamont-Doherty Earth Observatory of Columbia University, Palisades, NY, USA \\ ${ }^{6}$ NASA Goddard Space Flight Center, Greenbelt, MD, USA \\ ${ }^{7}$ Universities Space Research Association (USRA), GESTAR, Columbia, MD, USA \\ ${ }^{8}$ Centre National de Recherches Météorologiques, CNRS-Météo-France, UMR 3589, Toulouse, France \\ ${ }^{9}$ European Centre for Medium-Range Weather Forecasts, Reading, UK \\ ${ }^{10}$ Royal Netherlands Meteorological Institute, De Bilt, the Netherlands \\ ${ }^{11}$ Department of Chemistry, University of Cambridge, Cambridge, U.K. \\ ${ }^{12}$ National Centre for Atmospheric Science, U.K. \\ Correspondence to: Michael J. Prather (mprather@uci.edu)
}

\section{Contents of this file}

Figures $\mathrm{S} 1$ to $\mathrm{S} 8$

Table S1

This Supplementary Material includes figures and tables referenced in the main text and useful for understanding this work, but not essential to its findings. 

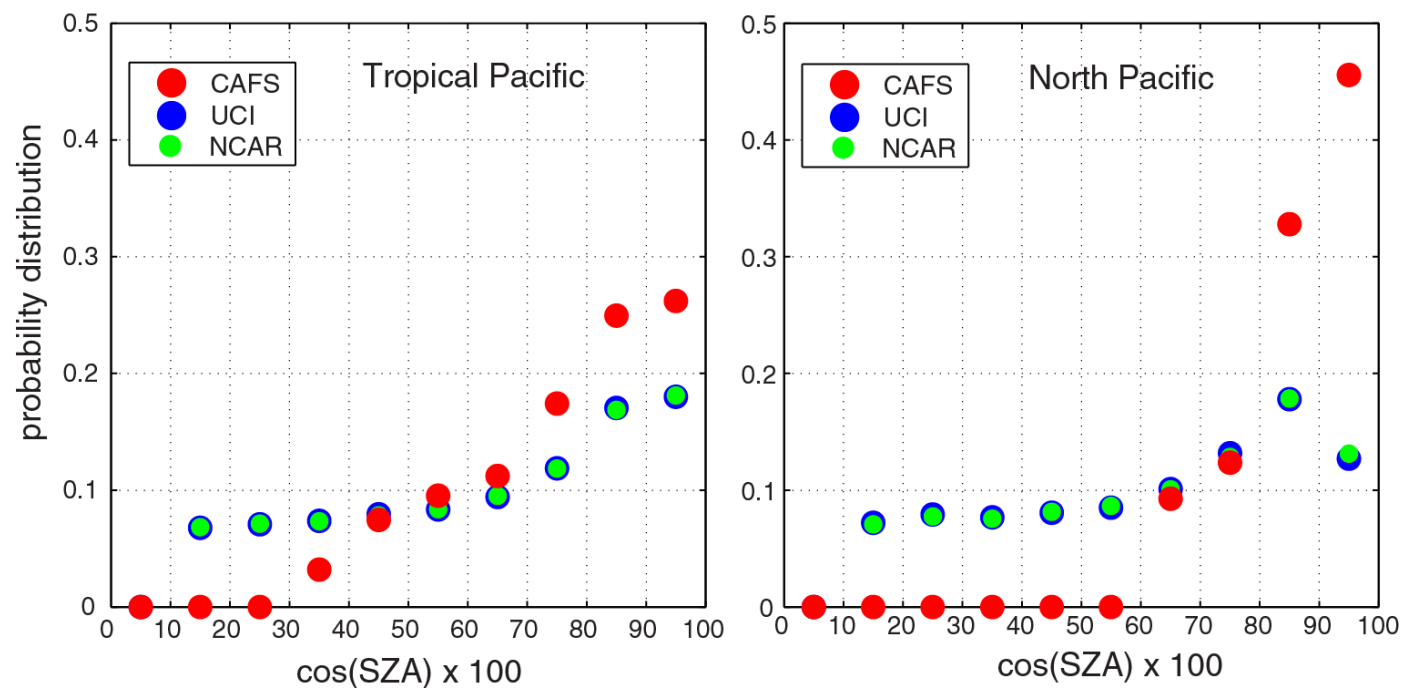

Figure S1. The probability distribution of solar zenith angles (SZAs) as sampled by ATom with the CAFS instrument (red) and by two models (UCI \& NCAR) using regular sampling over the two geographic blocks: (1, left) Tropical Pacific and (2, right) North Pacific. The points represent the relative number of samples in each 0.10 interval of $\cos (\mathrm{SZA})$. ATom flights in this region were generally centered about noon, and hence CAFs has a higher proportion of high SZAs. For most of the analysis here only J's with $\cos ($ sza) $>0.8$ are used, and with this restriction the number of CAFS measurements is 11,504 (block 1) and 4,867 (block 2). 

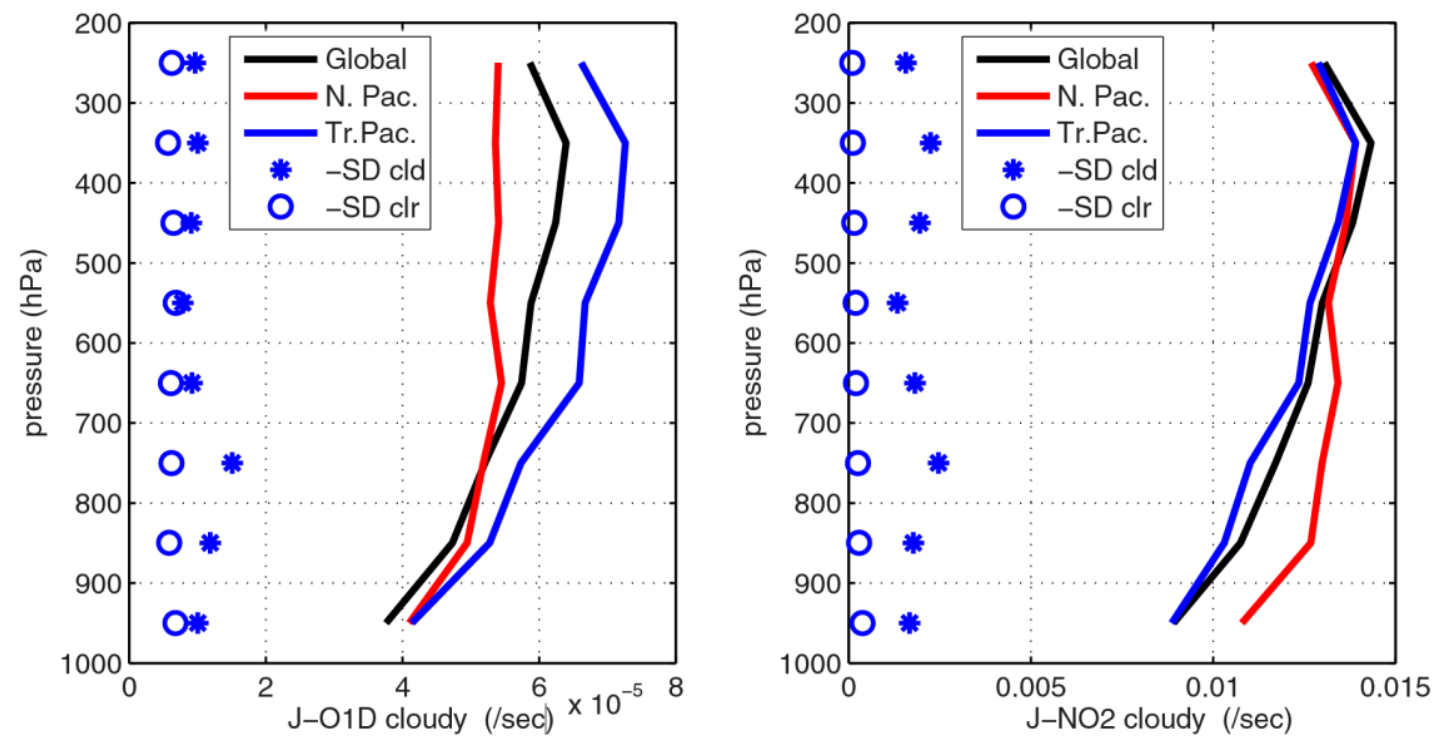

Figure S2. Mean CAFs profiles of J-O1D (left) and J-NO2 (right) from ATom-1 made under all-sky conditions for high-sun conditions, $\cos ($ sza) $>0.8$. The 3 geographic blocks shown here are the standard blocks 1 (blue, Tropical Pacific, $20^{\circ} \mathrm{S}-20^{\circ} \mathrm{N}$ x $160{ }^{\circ} \mathrm{E}-240^{\circ} \mathrm{E}$ ), and 2 (red, North Pacific, $20^{\circ} \mathrm{N}-50^{\circ} \mathrm{N} \mathrm{x} 170{ }^{\circ} \mathrm{E}-225^{\circ} \mathrm{E}$, plus a global block (black, $55^{\circ} \mathrm{S}-55^{\circ} \mathrm{N}$, all longitudes, including the Atlantic). Each 3-sec observation is averaged with equal weight in $100-\mathrm{hPa}$ pressure bins. The standard deviation for block 1 (blue, *) is shown along with that from the corresponding TUV model calculation for clear sky (blue, o). The patterns here are expected: J-O1D is sensitive to $\mathrm{O}_{3}$ absorption and hence has higher upper-tropospheric values in the tropics; J-NO2 is more sensitive to cloud scattering and hence has higher values in the in the lower troposphere of the North Pacific. The standard deviations show that J-O1D variance is driven by $\mathrm{O}_{3}$ and SZA, and not by clouds; while the J-NO2 shows the opposite.



Figure S3. Total ozone columns (in DU) versus latitude in August for 9 models and 8 years of OMI observations (2010-2017, Levelt et al., 2006; Veefkind et al., 2006). Most curves are the monthly zonal means, but some data are from a single day, or just the ATom flight track for several days (e.g., GFDL, explains the lack of smoothness). Differences here can explain only some of the spread in clear-sky J-O1D values in Figure 2. 

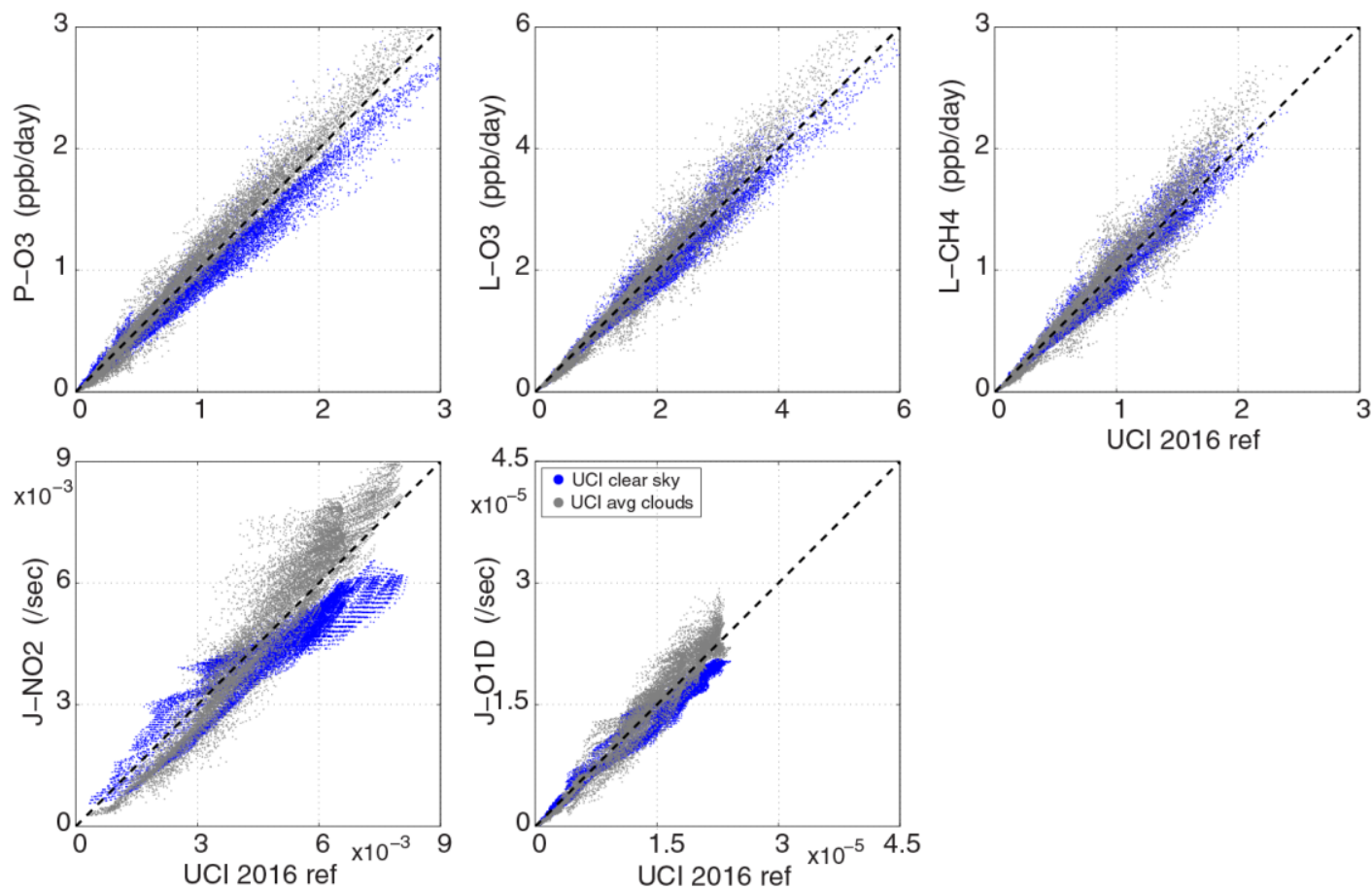

Figure S4. Effects of clear sky (blue points), simple averaged clouds (gray points), and fractional cloud overlap (the reference case, 1:1 dashed line) using the UCI CTM. X-axis is the same as the Y-axis, but for the reference model UCI 2016. Direct parcel-by-parcel comparison of modeled 24-hour reactivities (top row: P-O3, L-O3, L-CH4; all $\mathrm{ppb} /$ day) and photolysis rates (J-NO2, J-O1D; all /sec) calculated for a data stream of 14,880 simulated air parcels from $60^{\circ} \mathrm{S}$ to $60^{\circ} \mathrm{N}, 0.5 \mathrm{~km}$ to $12 \mathrm{~km}$ altitude, and along $180^{\circ} \mathrm{W}$, see Prather et al., 2018. Each point is an average of the 5 simulated dates in August (8/01, 8/06, 8/11, 8/16,8/21). UCI 2016 ref uses full cloud quadrature and the newly implemented decorrelation lengths for cloud overlap (Prather, 2015). From the figure, the different cloud treatments are clearly visible in the shifts in J-NO2 and J-O1D, and they have largest effect on P-O3 as compared with L-O3 and L-CH4. On average, the clear-sky simulation has 3-4\% lesser J-values and similar changes in all 3 reactivities. The averaged-cloud method has about $12 \%$ greater J-values (mostly above clouds), increasing reactivities by $5 \%(\mathrm{~L}-\mathrm{O} 3$ and $\mathrm{L}-\mathrm{CH} 4)$ to $10 \%(\mathrm{P}-\mathrm{O} 3)$. 



Figure S5. Histogram of the natural log of the ratio of cloudy-to-clear J values (J-O1D \& J-NO2), designated rlnJ, which is calculated from the 10-sec CAFS data and sorted into 3 pressure bins (blue, 100 - 300; red, 300 - 900; black, 900 - surface $\mathrm{hPa}$ ). Note that the upper level has a peak near 0.0, corresponding to clear sky; the lowest level extends more to values $<0$; and that the $\mathrm{N}$. Pacific for $<900 \mathrm{hPa}$ has a large number of cloud enhanced J-values (rlnJ $>0$ ). The CAFS data were binned at $0.01 \mathrm{rlnJ}$ and smoothed with a 1-2-1 filter six times. 

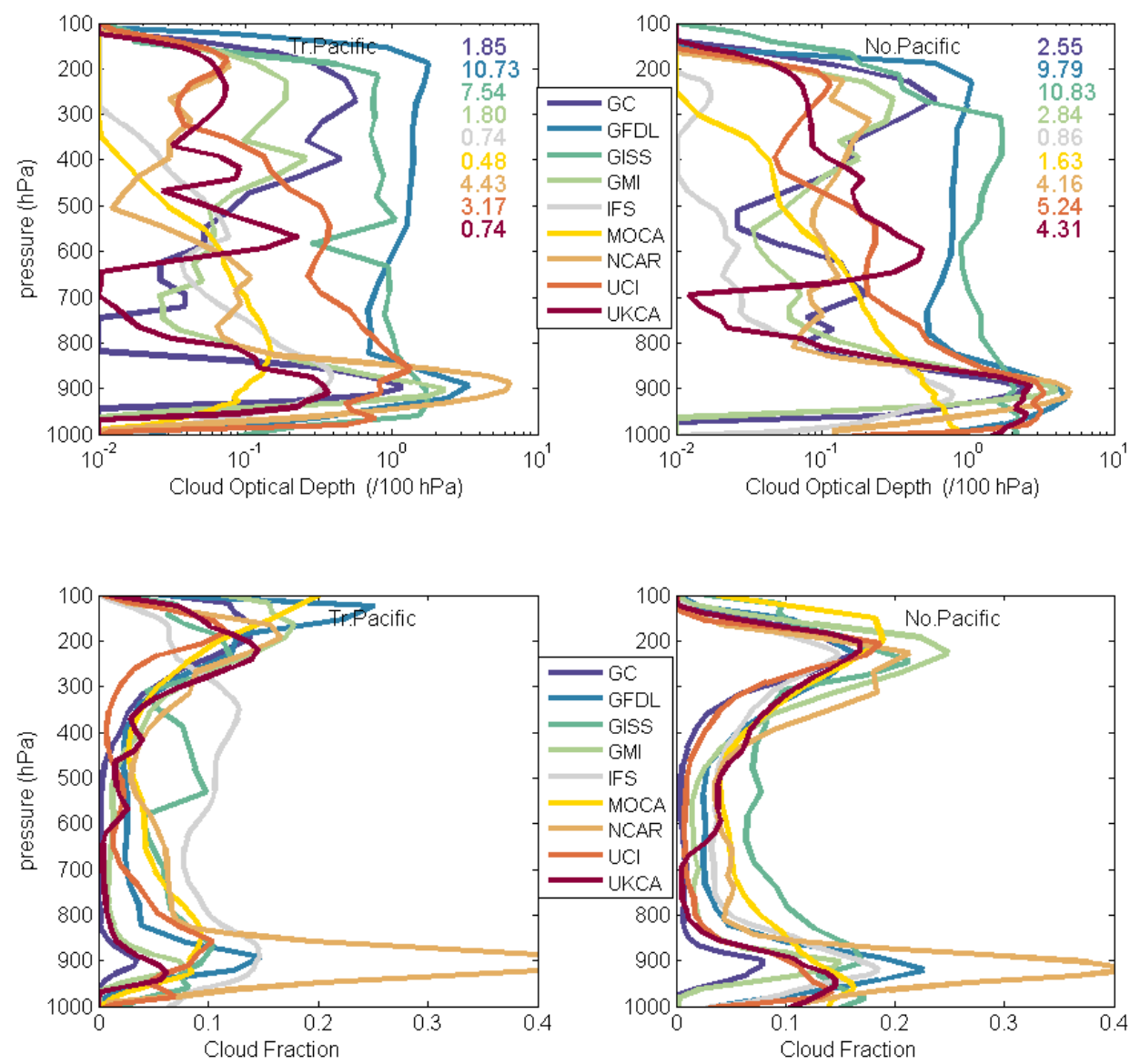

Figure S6. Averaged cloud optical depth (COD, at $\sim 600 \mathrm{~nm}$ and per $100 \mathrm{hPa}$ ) and cloud fraction (CF) over the two geographic blocks studied here blocks (Tropical Pacific, $20^{\circ} \mathrm{S}-20^{\circ} \mathrm{N}$ x $160{ }^{\circ} \mathrm{E}-240{ }^{\circ} \mathrm{E}$, and North Pacific, $20^{\circ} \mathrm{N}-$ $50{ }^{\circ} \mathrm{N} \mathrm{x} 170^{\circ} \mathrm{E}-225^{\circ} \mathrm{E}$ ). Averages are made over 24 hours for one day in mid-August as used in this paper. For these data (unlike the J-value statistics), all hours are weighted equally independent of solar zenith angle. Column total COD for each region is given in the order/color-indexed numbers on the right of each COD panel. 

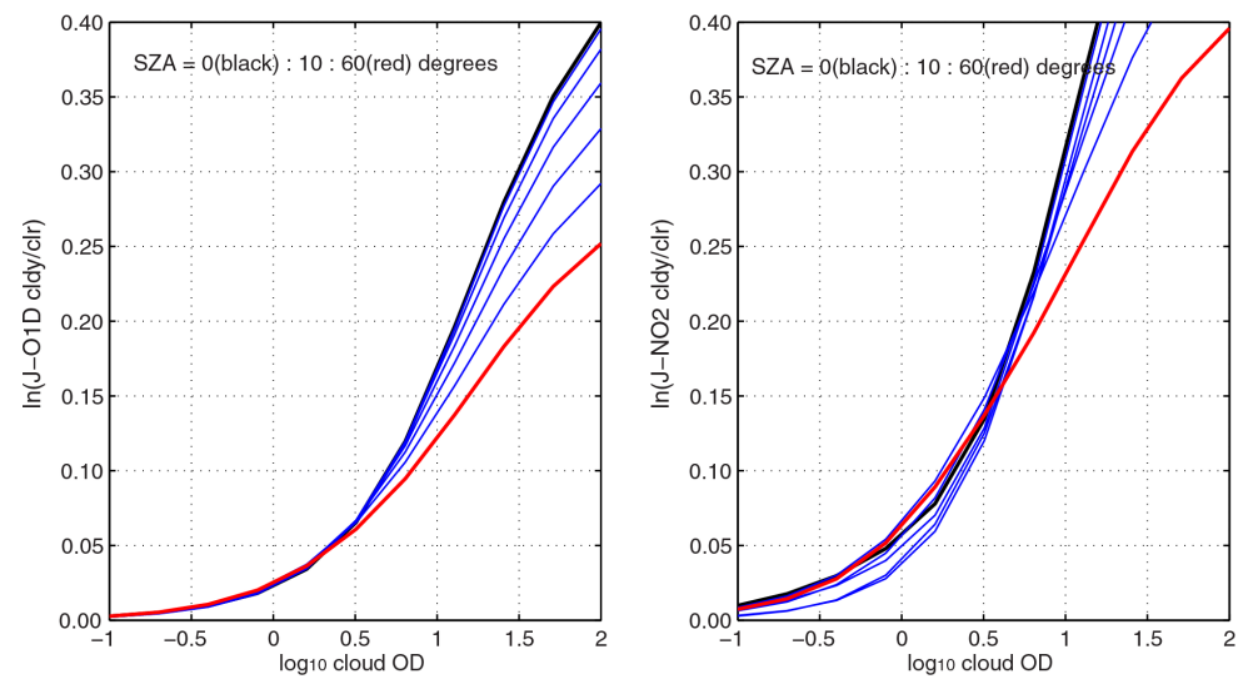

Figure S7. The ratio of J-cloudy/J-clear calculated for J-O1D (left) and J-NO2 (right) at $300 \mathrm{hPa}$ for a marine stratus cloud $(\mathrm{CF}=100 \%)$ at about $900 \mathrm{hPa}$. The natural $\log$ of the ratio $(\mathrm{rlnJ})$ is calculated for a cloud optical depth (COD) ranging from 0.1 to 100. The calculation uses Cloud-J (Prather, 2015), which does not scale COD, uses the truncated (order 8) phase function, and applies a constant lower boundary albedo $=0.05$. The incident SZA ranges from $0^{\circ}$ (black) to $60^{\circ}$ (red) in $10^{\circ}$ intervals (blue). The rlnJ's in this paper are restricted to $0^{\circ}-40^{\circ}$. A $5 \%$ enhancement $(\mathrm{rlnJ}=0.05$ ) occurs at $\mathrm{COD}=2$ for $\mathrm{J}-\mathrm{O} 1 \mathrm{D}$ and $\mathrm{COD}=1$ for $\mathrm{J}-\mathrm{NO} 2$, demonstrating the greater sensitivity of J-NO2 to clouds.
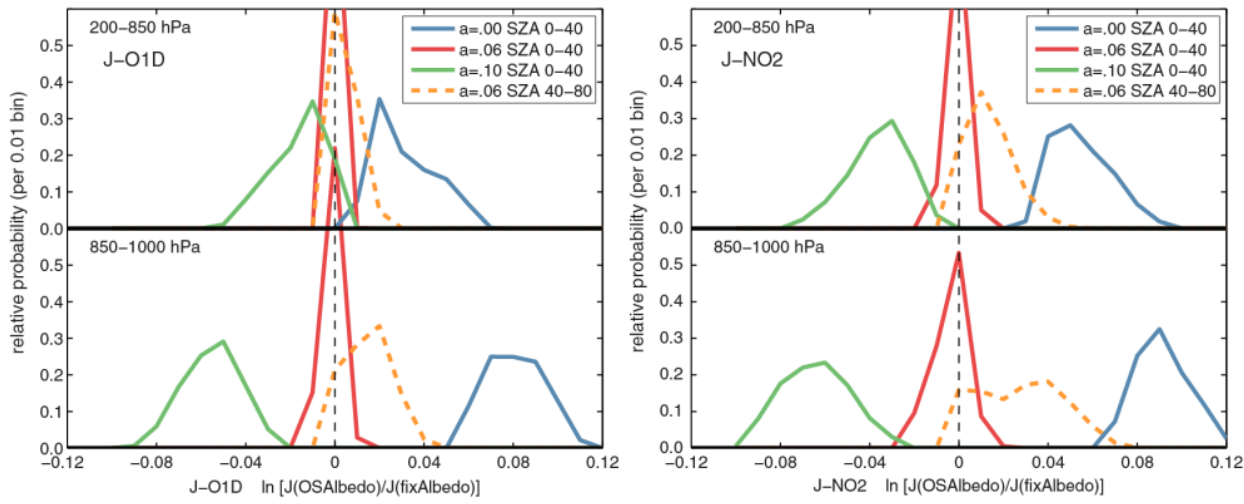

Figure S8. Probability distribution of the natural log of the ratio of J-values calculated using an interactive ocean surface albedo (OSA) to J-values using a fixed albedo. J-O1D values (left) and J-NO2 values (right) assume clear skies for both OSA and fixed-albedo. This format is similar to Figure 4. The interactive OSA model includes a dependence on wavelength and incident-angle now in Cloud-J v8, see text. The fixed albedo is denoted by 'a =' in the legend. These distributions show the relative error in J-values calculated in typical models using a fixed albedo instead of the more physically based OSA models (Séférian et al., 2018). For both cases the reflected sunlight is assumed to be isotropic. The OSA depends on surface wind (sampled uniformly from 1 to $21 \mathrm{~m} / \mathrm{s}$ ) and chlorophyll abundance (sampled uniformly in $\log$ from 0.01 to $30 \mathrm{mg} / \mathrm{m}^{3}$ ). The plots are also split between the lowermost troposphere (lower panels, >850 hPa) and free troposphere (upper, $200-850 \mathrm{hPa}$ ). 


\begin{tabular}{|c|c|c|c|}
\hline \multicolumn{4}{|c|}{ Table S1. Model contact information } \\
\hline short name & long name & POCs for these simulations & \\
\hline CAFS & --- & Sam Hall<halls@ucar.edu> & Kirk Ullmann <ullmannk@ucar.edu> \\
\hline GC & GEOSChem & Murray, Lee <lee.murray@ rochester.edu> & \\
\hline GFDL & GFDL AM3 & $\begin{array}{l}\text { Arlene Fiore } \\
\text { <amfiore@1deo.columbia.edu> }\end{array}$ & Gustavo Correa <gus@ldeo.columbia.edu> \\
\hline GISS & GISS ModelE2 & Murray, Lee <lee.murray@ rochester.edu> & \\
\hline GMI & GSFC GMI & $\begin{array}{l}\text { Sarah A. Strode } \\
\text { <Sarah.A.Strode@nasa.gov> }\end{array}$ & $\begin{array}{l}\text { Stephen Steenrod } \\
\text { <Stephen.D.Steenrod@nasa.gov> }\end{array}$ \\
\hline IFS & ECMWF IFS & $\begin{array}{l}\text { Johannes Flemming } \\
<\text { johannes.flemming@ecmwf.int> }\end{array}$ & Vincent Huijnen <vincent.huijnen@knmi.nl> \\
\hline MOCA & MOCAGE & Beatrice Josse <beatrice.josse@ meteo.fr> & Jonathan Guth <jonathan.guth@meteo.fr> \\
\hline NCAR & CESM & $\begin{array}{l}\text { Jean-Francois Lamarque } \\
<\text { lamar@ucar.edu> }\end{array}$ & \\
\hline UCI & UCI CTM & Michael Prather <mprather@uci.edu> & Clare Flynn <claref@uci.edu> \\
\hline UKCA & UKCA & $\begin{array}{l}\text { Luke Aabraham } \\
<\text { luke.abraham@atm.ch.cam.ac.uk> }\end{array}$ & $\begin{array}{l}\text { Alex Archibald <ata27@cam.ac.uk>, } \\
\text { Marcus Koehler <m.koehler@uea.ac.uk> }\end{array}$ \\
\hline
\end{tabular}

